\title{
Creating a Virtual Learning Environment
}

\author{
György Hampel ${ }^{1}$, Kinga Dancsházy ${ }^{2}$
}

\section{N F O}

Received 29 Nov. 2013

Accepted 24 Jan. 2014

Available on-line 10 July. 2014

Responsible Editor: K. Rajkai

\section{Keywords:}

Developing e-learning material, virtual learning environment, on-line toolkit, learning management system

\section{$\underline{\text { A B S T R A C T }}$}

Creating a virtual learning environment may be useful to acquire knowledge in some circumstances. A Learning Management System is essential to manage a virtual learning environment. There are numerous steps of creating an e-learning curriculum. In the described three-year international project the goal was to develop an e-learning system with the following logical development scale: (1) Specification of the needs of the target group; (2) Development of the on-line toolkit; (3) Development of the training material; (4) Training of the e-tutors; (5) Development of the methodology to test the training material; (6) Pilot testing on the target group; (7) Accreditation of the modules; (8) Dissemination and promotion activities. This paper contains a brief description of the above mentioned development process which resulted in an e-learning material that can be used to prepare agrarian specialists to prepare for today's modern world and to be a successful member of the information society.

\section{Introduction}

This paper gives a short summary about three years of e-learning development in an international cooperation. The main goal of the project was to create an e-learning material and its learning management system for e-workers and e-managers which enables them to successfully integrate into the information society.

Learning materials assisting the acquisition of knowledge are created nowadays in several scientific disciplines which are either stand-alone or available through a Learning Management System. Agricultural sciences are no different.

E-learning materials with their learning management systems - mainly based on open-source software - are implemented (Nauris, 2010), examined (Alecu et al., 2011) and used in several agricultural higher education institutes (Herdon, Lengyel, 2008). Since training is essential for the future employee (the worker) and employer (the manager) to become competitive in a rapidly changing environment, the development efforts are backed by EU programmes and funding, like the Leonardo NewCAP project (New European Standards in the Context of Reformed EU Common Agricultural Policy) and the AVARES project (Enhance Attractiveness of Renewable Energy Training by Virtual Reality) (Palkova et al., 2013).

In recent years papers were published about the benefits of the involvement of computers and the internet in education. (Sideridis et al., 2010). Some of the main benefits are as follows: it is studentcentred, self-directed and self-paced, interactive and hands-on, flexible, provides consistent and effective training (DNA Analyst Training, 2013). To be able to transfer the necessary information and to achieve success, the range of different technology should be carefully selected by weighing several factors (Gaceu et al., 2010).

It should also be clear that this modern technology is not a panacea, as - for example - the summarizing paper of Workshop on Virtual Learning Environment (Dillenbourg, 2000) states: It has

\author{
${ }^{1}$ György Hampel \\ University of Szeged Faculty of Engineering, 6720 Szeged, Mars tér 7, Hungary \\ hampel@mk.u-szeged.hu \\ ${ }^{2}$ Kinga Dancsházy \\ Inno-Motive Nonprofit Ltd., 7623 Pécs, Szabadság út 34, Hungary \\ kinga.dancshazy@innomotive.hu
}


some potential effects, although it is difficult to turn it to actual ones, or at least to measure the positive effects. So, there is hardly any scientific proof of the superiority of the modern technologies.

Nevertheless, creating a virtual learning environment may be useful for students to acquire knowledge in some circumstances. What can be considered a virtual learning environment? According to Dillenbourg (Dillenbourg, 2000) it is a designed information space which is not restricted to distance education; it is a social space which integrates multiple tools where the space is explicitly represented, it also overlaps physical environment where the students are not only active, but also actors.

A Learning Management System is essential to manage a virtual learning environment. The task of this system is to identify, to record and to follow the students participating in the educational process and to connect the users to their respective courses according to their roles and competencies (Gaceu et al., 2009).

When creating the learning materials and their learning environment, the learning management system, it is suggested to follow some rules or standards which may more likely lead to success. Depending on the goals to be achieved, the type of the e-learning material, the aspiration level of the tutors (or the development team) and the available technical and financial possibilities there are basically two methods:

- Agile development: In this case the elements of the information systems are created separately and combined, integrated later into a larger system (Munkhtsetseg, Uyanga, 2013).

- Waterfall development: A more preferred method is based on the information system lifecycle processes introduced in IEEE/EIA 12207 "Standard for Information Technology - Software Life Cycle Processes" (Lee et al., 2002). The software development life-cycle can be described in five steps by the waterfall model: (1) Project planning; (2) Requirement definition; (3) Design and development; (4) Integration and testing; (5) Installation and maintenance. The standard defines processes covering the entire life-cycle of a software system from the concept to retirement. The steps are well-tried to develop complex, integrated information systems (figure 1).

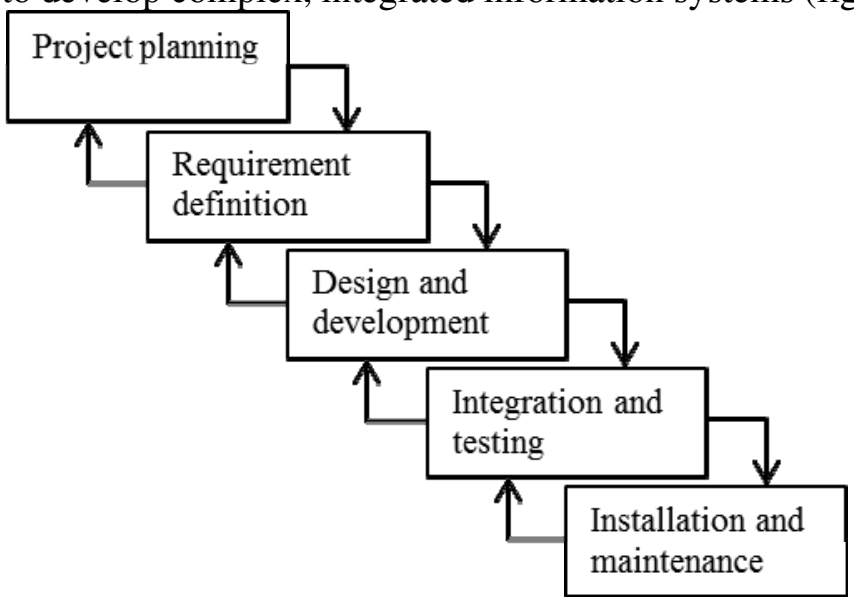

Figure 1. Waterfall model of the software development life-cycle (source: Paulins, 2010)

The ADDIE model (Analysis, Design, Development, Implementation and Evaluation) is a framework training e-learning developers may also use. The model which is a recognized and proven instructional design methodology (Delf, 2013) describes guidelines useful to build effective training and performance support tools (Morrison et al, 2010). The guide to e-learning methodologies published by the Food and Agriculture Organization of the United Nations (Ghirardini, 2011) also recommends the ADDIE model as a suitable methodology to develop e-learning materials (figure 2). Ghirardini draws attention to the importance of the professional roles, the required technology and media related skills of the participants taking part in the development. 

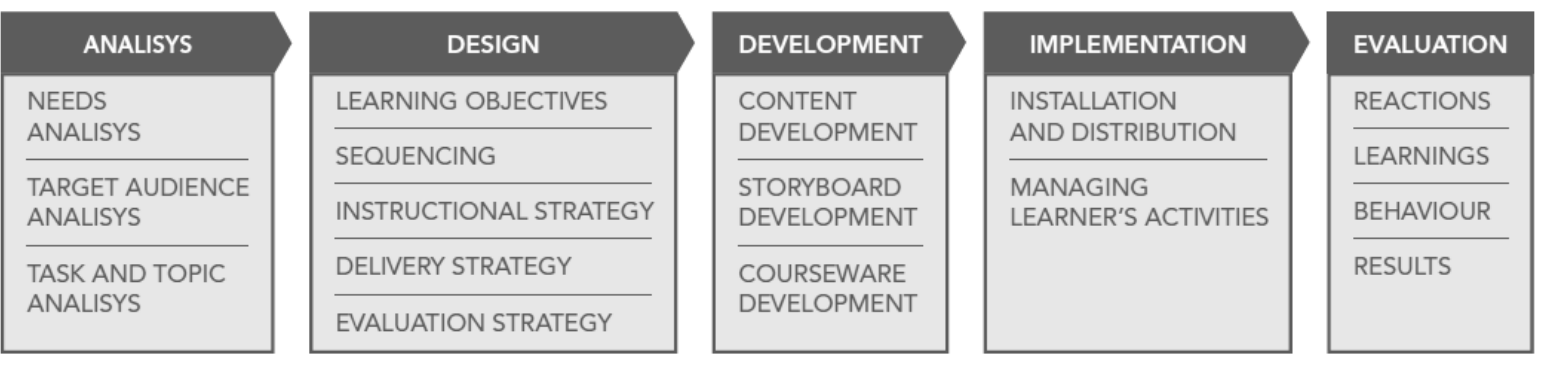

Figure 2. The ADDIE model for e-learning (source: Ghirardini, 2011)

Since we are talking about software, ISO 9126 standard assuring software quality (functionality, reliability, usability, efficiency, maintainability and portability) can be taken into consideration (AlQutaish, 2009). Other useful tools and criteria are also available to maintain the quality of e-learning programmes, including the Heuristic Evaluation Instrument and Protocol for E-learning Programs (Benson et al., 2001) or the LMS Evaluation Tool User Guide (3waynet, 2004).

\section{The e-material development project}

The main goal of the international development project financed by the Leonardo da Vinci programme was to provide practical and useful support for the preparation of small and medium-sized enterprises for working in a virtual environment and to be able to be useful members of virtual teams.

The participants of the international consortium were

- Inno-Motive Nonprofit Ltd., an accredited education institute from Szeged (Hungary) with wide experience in co-ordinating international projects and promoting alternative employment, competency based training and education;

- Bit media e-Learning solution GmbH \& Co KG from Graz (Austria) with experience in developing e-learning material and learning management systems and also in providing e-learning content through the web;

- West Lithuania Business College from Klaipeda (Lithuania) with experience in creating, converting and using e-learning materials in higher education;

- Inovaformação - Prestaçao de Serviços de Formaçao Profissional Lda from Matosinhos (Portugal), an international company experienced in promoting innovation, training and supplying advisory services for SMEs and higher education institutions.

The e-learning development concept was based on a logical scale defined by the consortium members built on the waterfall model of software development, but also including the experiences of the Austrian partner in this field (Inno-Motive et al., 2010):

(1) The specification of the needs of the target group;

(2) The development of the on-line toolkit;

(3) The development of the training material;

(4) The training of the e-tutors who help the students to acquire the knowledge;

(5) The development of the methodology for testing the training material;

(6) A pilot testing on the target group;

(7) The accreditation of the modules;

(8) Dissemination and promotion activities to promote the finished e-learning material;

Mainly due to the inclusion of EU funding sources, the project followed a timetable which included several personal meetings and web conferences of the project staff involved to disseminate information, documenting and reporting of progress to stakeholders and, of course, a strict budget. The total budget of the project was 406753 Euros and the EU funding was 75 percent. The detailed description of these falls outside the scope of this paper. 


\subsection{The specification of the needs of the target group}

After specifying the main objectives, defining the partners involved in the project, budgeting, obtaining the financial support of the EU and the distribution of the different tasks between the project staff, the first thing to do was to conduct a survey.

The aim of the survey was to identify the necessary competencies of the target groups in the participating countries and to explore and summarise the coherence with national training needs of the target groups. The survey involved 200 small and medium-sized enterprises from Austria, Hungary, Lithuania and Portugal. Each partner conducted the survey in its own country. The results were synthetized in a sectorial survey report (figure 3) by the Portuguese Inovaformação. Their findings provided input to determine the specific content of the e-training materials.

Based on the survey results, important competencies could be identified which showed what skills have to be assessed by the on-line toolkit and then developed by the e-learning material. The development of the curriculum was highly based on the survey results.

\section{Competencies of e-workers}

\begin{tabular}{|l|c|c|c|c|}
\hline How do you assess the importance of the following competencies of e-workers to work in an e-working environment? \\
\hline & Irrelevant & Relevant & Important & Very important \\
\hline ICT knowledge & 0 & 2 & 21 & 27 \\
\hline Quality Awareness & 0 & 2 & 28 & 20 \\
\hline Continuous Improvement & 0 & 6 & 21 & 23 \\
\hline Customer/Project Orientation & 1 & 9 & 19 & 21 \\
\hline Cooperation & 0 & 6 & 18 & 26 \\
\hline Reliability & 0 & 0 & 14 & 36 \\
\hline Initiative & 2 & 16 & 21 & 11 \\
\hline Planning & 1 & 20 & 19 & 10 \\
\hline Managing Change & 5 & 14 & 21 & 10 \\
\hline Internet Communication & 0 & 2 & 18 & 30 \\
\hline Lifelong Learning & 2 & 9 & 18 & 21 \\
\hline Independency & 0 & 3 & 11 & 36 \\
\hline
\end{tabular}

\section{Competencies of e-workers}

How do you assess the importance of the following competencies of e-workers to work in an e-working environment?

\begin{tabular}{|l|c|c|c|c|}
\hline & Irrelevant & Relevant & Important & Very important \\
\hline ICT knowledge & 1 & 5 & 23 & 21 \\
\hline Quality Awareness & 0 & 6 & 12 & 32 \\
\hline Continuous Improvement & 1 & 8 & 24 & 17 \\
\hline Customer/Project Orientation & 4 & 4 & 17 & 25 \\
\hline Cooperation & 0 & 7 & 23 & 20 \\
\hline Reliability & 0 & 2 & 6 & 42 \\
\hline Initiative & 2 & 17 & 26 & 5 \\
\hline Planning & 2 & 16 & 30 & 2 \\
\hline Managing Change & 0 & 11 & 16 & 23 \\
\hline Internet Communication & 0 & 2 & 12 & 36 \\
\hline Lifelong Learning & 0 & 13 & 16 & 21 \\
\hline Independency & & 6 & 17 & 27 \\
\hline
\end{tabular}

Figure 3. Sample of survey results of Hungary (top) and Austria (bottom) from the Sectoral Survey Report. Numbers show number of answers. (Source: Inovaformação Lda., 2010)

\subsection{The development of the on-line toolkit}

The e-learning material has to be tailored to the students' needs and skills, so it is necessary to identify whether he or she possesses the right competencies. To achieve this, a "Competency ToolKit" was developed in the co-operation of the Hungarian and the Austrian partner. The tool allowed the identification of the missing competencies: by using the toolkit at the beginning of the e-learning 
course, a self-assessment can be conducted and the personal development plan can be created, specifying the training needs of the participant (figure 4). Originally the plan was to create an entertaining, game-like tool with graphics, animated cartoon characters and sound, but unfortunately that did not fit into the budget, so eventually the team had to be satisfied with a text-only version.

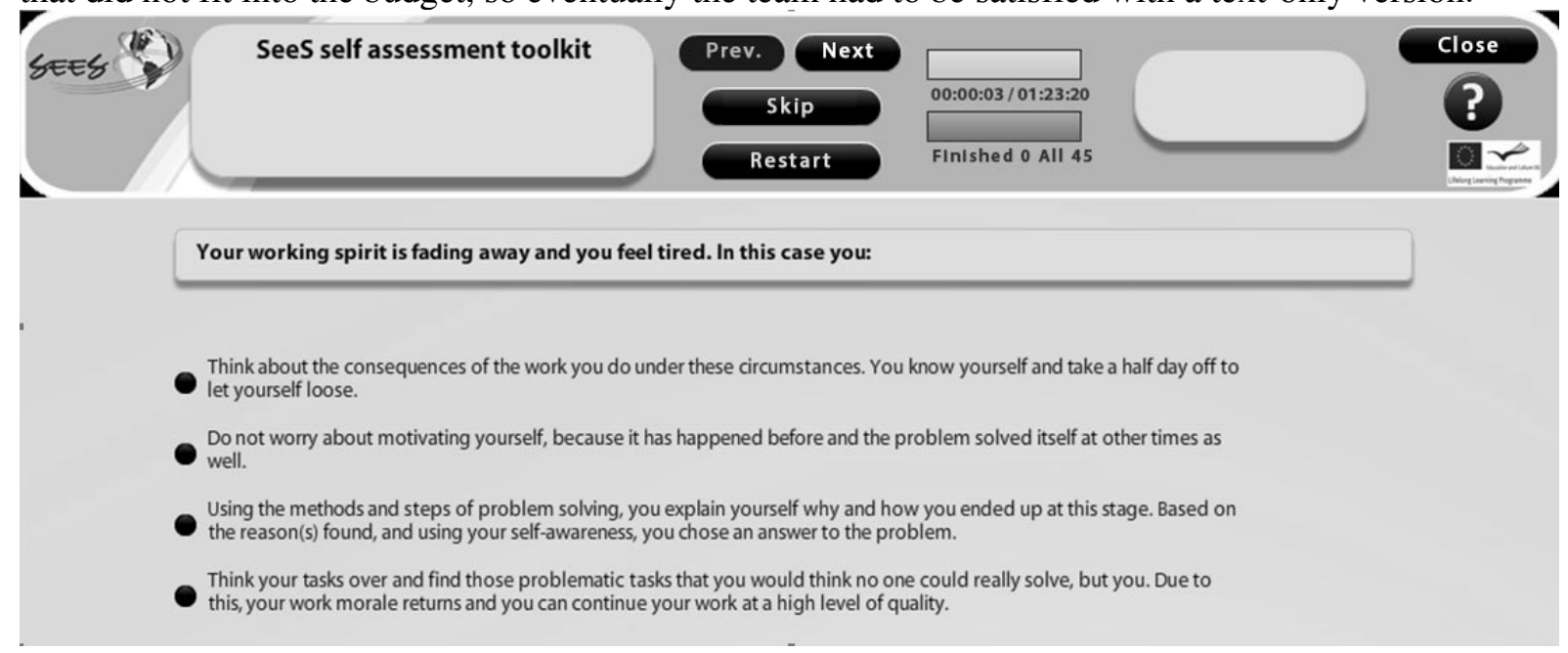

\begin{tabular}{|c|c|c|}
\hline Category & Progress (\%) & Feedback \\
\hline Change management (M) & 50 & $\begin{array}{l}\text { Although you know that during your work changes need to be made, you do not think } \\
\text { these can be pre-planned. You tend to react to changes in an ad hoc way. This often } \\
\text { results in using good old methods instead of having flexible changes that are more } \\
\text { appropriate for the situation. }\end{array}$ \\
\hline Quality (M) & 40 & $\begin{array}{l}\text { You know that quality management is a must in every organization. You have your } \\
\text { reservations about its effectiveness and existence. Your answers indicated though that you } \\
\text { are formally taking part in working out such policies. Based on the above, you do not } \\
\text { consider some of the aspects necessary for you. Most likely, one of the very important } \\
\text { reasons for this is your authoritarian leadership style. }\end{array}$ \\
\hline
\end{tabular}

Figure 4. Sample question and results of the on-line toolkit (first test version during software development)

\subsection{The development of the training material}

Twelve e-learning modules were proposed based also on the survey results which would help workers to thrive at work and in life. Three modules, including leadership, change management and performance appraisal were planned explicitly for managers, another three modules were planned for workers which were time management, decision making and problem solving and the other six modules including e-communication, team building, quality awareness, motivation, conflict handling and life-long learning were proposed as shared learning materials for both groups. This task was carried out by the Hungarian coordinator and approved by the project partners.

The curricula were created in accordance with the steps devised by Bitmedia:

Step 1: Shaping up the rough concept: The target of the rough concept was to determine the course structure (table 1), the main principles, aims and the methodological, didactical approach (table 2). 
Table 1. The element and the description of the learning modules

\begin{tabular}{|l|l|}
\hline Elements & Description \\
\hline Navigation elements & Bottom left \\
\hline Layout design & According to style guides \\
\hline Extras (book marks) & To be defined \\
\hline Notes-drawer & Yes \\
\hline Glossary-drawer & Yes \\
\hline Topics-drawer & Yes \\
\hline Video-drawer & Yes \\
\hline Speaker & English \\
\hline Audio on/off button & Yes \\
\hline Types of interactive elements & To be defined after finalization of first rough concept \\
\hline Graphics & $\begin{array}{l}\text { Will be delivered by responsible person, processed } \\
\text { and animated by Bitmedia }\end{array}$ \\
\hline Animations & Approximately 1 animation per module \\
\hline Self test & At the end of each module \\
\hline Help & To be activated by a button \\
\hline
\end{tabular}

Source: Bit media e-learning solutions, 2009

Table 2. Principles, aims and didactical approach of the learning development project

\begin{tabular}{|l|l|l|}
\hline Principle & Aim & Methodical / didactical approach \\
\hline $\begin{array}{l}\text { Practice } \\
\text { oriented }\end{array}$ & $\begin{array}{l}\text { The learners are brought up to speed and } \\
\text { sensitized to the subject using examples } \\
\text { from their everyday work situations. }\end{array}$ & $\begin{array}{l}\text { The learners will be made aware of the relevance } \\
\text { and application of the learning material to their } \\
\text { everyday work through the implementation of the } \\
\text { material in everyday situations etc. }\end{array}$ \\
\hline $\begin{array}{l}\text { Action } \\
\text { orientation }\end{array}$ & $\begin{array}{l}\text { The learners are motivated by } \\
\text { interactivity in the learning process } \\
\text { which develops their active competence } \\
\text { in the application of the material. }\end{array}$ & $\begin{array}{l}\text { Exercises are not only used for checking learners' } \\
\text { knowledge, but also for transferring it by simulating } \\
\text { situations where decisions and choices have to be } \\
\text { made on the basis of actual case studies. }\end{array}$ \\
\hline $\begin{array}{l}\text { Multimedia } \\
\text { stimulation }\end{array}$ & $\begin{array}{l}\text { The learners are stimulated optically and } \\
\text { through multiple channels in order to } \\
\text { appeal to the different types of learners } \\
\text { and to assure their learning success. }\end{array}$ & $\begin{array}{l}\text { Application of graphically attractive and } \\
\text { didactically effective visualizations (static graphics } \\
\text { and animations and audio). }\end{array}$ \\
\hline
\end{tabular}

Source: Bit media e-learning solutions, 2009

A comprehensive time schedule was also set up which contained all essential phases to complete the learning material.

Step 2: Elaboration of the detailed concept: As it represents an intermediate state between the rough concept and the script, this was a time consuming process. The position of the planned screen page within the learning programme, the unit title, the learning steps (screen pages), the design of multimedia elements, the content description (i. e. the learning goal) and the reference on external sources were designed. Developing the rough concept and the detailed concept was performed in collaboration by all members of the consortium on face-to-face meetings and virtual seminars, video conferences. Due to budget constraints and possible cultural differences of the participating countries the partners have eventually decided not to include video recordings of role plays, but have not fully abandoned the idea. Later, in case the learning material proves to be successful, the videos can be created and integrated into the next version.

Step 3: Creating storyboards (script) and visualisation: The script described the structure as well as the set-up of all screen pages of the learning programme. It also contained all the texts on-screen and the description of all the multimedia tools that had to be produced (figure 5). This task was distributed among all consortium members. 


\begin{tabular}{|c|c|c|}
\hline ID: $x \_y \_z$ & \multirow{2}{*}{\multicolumn{2}{|c|}{ Title of the page: $x \times x \times x x \times x \times x x x x$}} \\
\hline Template: Infopage & & \\
\hline \multicolumn{2}{|c|}{$\begin{array}{l}\text { Text Text Text Text Text Text Text Text Text Text Text Text Text } \\
\text { Text Text Text Text Text Text Text Text Text Text Text Text Text } \\
\text { Text Text Text Text Text Text Text Text Text Text Text Text Text } \\
\text { Text Text Text Text Text Text Text Text Text Text Text Text Text } \\
\text { Text Text Text Text Text Text Text Text Text Text Text Text Text } \\
\text { Text Text Text Text Text Text Text Text Text Text Text Text Text } \\
\text { Text Text Text Text }\end{array}$} & $\begin{array}{l}\text { Instruction: } \\
\text { The page can be } \\
\text { designed arbitrary } \\
\text { with text, graphics } \\
\text { or animations. } \\
\text { Didactic advice: Do } \\
\text { not include too } \\
\text { much subject } \\
\text { matters -> } \\
\text { "appropriate for the } \\
\text { screen". }\end{array}$ \\
\hline $\begin{array}{l}\text { Text Text Text Text } \\
\text { Text Text Text Text } \\
\text { Text Text Text Text } \\
\text { Text Text Text Text }\end{array}$ & $\begin{array}{l}\text { xt Text Text Text Text Text Text Text } \\
\text { at Text Text Text Text Text Text Text } \\
\text { at Text Text Text Text Text Text Text } \\
\text { at Text Text Text Text Text Text Text }\end{array}$ & $\begin{array}{l}\text { If there is not } \\
\text { enough space for } \\
\text { the description of } \\
\text { the graphics or } \\
\text { animations, use the } \\
\text { graphic template. }\end{array}$ \\
\hline
\end{tabular}

Figure 5. Sample from the script template for script writers (Source: Bit media e-learning solutions, 2009)

Step 4: Transforming the material into electronic format (creating the prototype): The technical realization of the curricula. Since they had the most experience in this field, it was reasonable to entrust the task to the Austrian partner. During the prototyping a drawback has emerged: Bitmedia's proprietary system was used which would probably make it difficult to disseminate the finished elearning material in the future. This is problem still needs to be solved.

Internal evaluation and content checks of the materials were carried out in all four steps. The project members evaluated each other's work. To achieve this, an evaluation handbook (Hampel, 2010) based an e-learning content guidelines, was also accepted beforehand by the partners. The evaluation criteria feedback forms helped the evaluation of the modules before the testing and the finalisation (figure 6).

The multi-language modules were first prepared in English and then they were translated and localized into the languages of the partners: German, Hungarian, Lithuanian and Portuguese. While the translation seemed relatively simple, the developing team had to overcome some difficulties during the localization of the learning material which arose from social and cultural differences of the participating countries.

\subsection{The training of the e-tutors who help the students to acquire the knowledge}

All project partners have conducted local e-tutor trainings, where the goal was to introduce the concept and to show the developed tools and their use. Twenty tutors were trained, five from each participating country. The teachers became familiar with the tasks of an e-tutor and with methods to use while tutoring the e-learners. After the training the e-tutors were in the possession of the knowledge to assist students while learning the e-modules. This was important because e-learning on its own is usually less effective than "blended learning".

\subsection{The development of the methodology for testing the training material}

A good way to test a training material is to measure how well students perform in real-life situations in a simulation after they have learned the content of the course. Therefore, different 
situations, scenarios were created from real-life cases by the project partners. The generated problems were to be solved by collaboration and by making decisions in a virtual environment with the use of online communication tools.

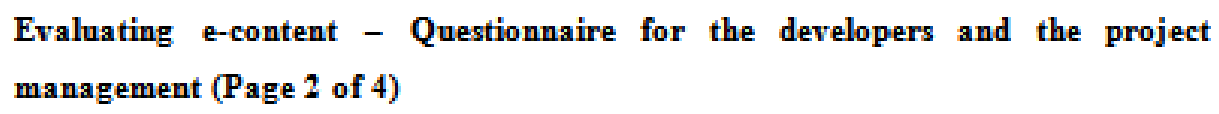

Apply a rating from 1 to 5 for each statement below, with 1 indicating total disagreement, and $\mathbf{5}$ indicating total agreement.

\begin{tabular}{|l|l|}
\hline Statement & Rating \\
\hline $\begin{array}{l}\text { 1. The content covers all of the objectives of the course, and is it all } \\
\text { related to the objectives. }\end{array}$ & 12345 \\
\hline 2. The content reflects the real world. & 12345 \\
\hline 3. The presented information is relevant concerning the target group. & 12345 \\
\hline 4. The content is accurate and self-contained. & 12345 \\
\hline 5. The content is practice oriented. & 12345 \\
\hline \begin{tabular}{l} 
6. The content is action oriented. \\
\hline 7. The tasks are problem-based.
\end{tabular} & 12345 \\
\hline $\begin{array}{l}\text { 8. The different types of informationcarriers (text, sound and graphics) } \\
\text { are appropriately used. }\end{array}$ & 12345 \\
\hline $\begin{array}{l}\text { 9. The content is appropriate considering gender, age, race, religion and } \\
\text { learning ability. }\end{array}$ & 12345 \\
\hline 10. The page layout is consistent and well designed. & 12345 \\
\hline $\begin{array}{l}\text { 11. The text is large enough to be easily read at most common screen } \\
\text { resolutions. }\end{array}$ & 12345 \\
\hline 12. The used colours are appropriate. & 12345 \\
\hline 13. The audio and video is understandable. & 12345 \\
\hline
\end{tabular}

Figure 6. Sample of the evaluation forms (Source: Hampel, 2010)

\subsection{A pilot testing on the target group}

A pilot testing was conducted on the prototype of the learning material. The participants were volunteers, representatives from small and medium sized enterprises and educational institutions from the countries of the consortium members. The twenty volunteers (five from each country) formed four groups. First of all they had to identify their own competencies and skills to be developed with the online toolkit, which gave them feedback regarding their preparedness. With this input, the participants have learned the material using the e-learning modules before the simulation. The actual simulation started only after completing all the above mentioned tasks.

All the participants of the pilot testing had to make obligation for seven working days and allocate 2 hours of their time every day for online work and some time for homework. During these hours they had to do specified tasks connected to a marketing case of an international company.

After each online meeting every team members had to fill in an online evaluation form. The e-tutor evaluated their performance and made comments regarding the techniques learned in the e-learning material. 
After completing the pilot testing, an evaluation was done by the volunteers. Their feedback, the remarks and the experiences of the pilot testing were built into the final e-learning product.

\subsection{The accreditation of the modules}

Once the local language versions were available, the developed e-learning modules were embedded in the local training plans of the partnering institutions. From that point, all adult educational institutions can officially make the content available in their portfolios. This allows the future expatiation and also provides an opportunity for building new programmes and projects based on the completed curriculum.

\subsection{Dissemination and promotion activities to promote the finished e-learning material}

Big effort was made to spread the e-learning material after the product was finalized. The necessary information was available in the languages of the project partners. Traditional promotion materials like announcements, newsletters and flyers were designed and were continuously distributed to all sector stakeholders, involving small and medium sized enterprises, educational institutions, human resource managers, vocational education representatives and research and development institutions. Local dissemination seminars were organised by the partners in their countries across all administrative levels and through the associated partners. The project partners also participated in local fairs, conferences and in events organised locally or by the EU Lifelong Learning Programme.

\section{Conclusion}

It is a known fact that our world is rapidly changing. The economic crisis has a great effect on the business world today. The new, emerging learning methods backed by ICT are essential to effectively acquire knowledge. Using them can prepare learners to accept the fact that modern ICT is essential to acquire information and succeed in business, too.

Creating an e-learning curriculum and presenting it through a learning management system as a virtual learning environment is a time consuming and resource hungry task. It requires a lot of experience from different fields and coordinated work of many people from the very beginning until the dissemination of the finished product. The product is of course, in reality, never finished and has to be improved from time to time.

Professionals working in the agriculture of the future have to be aware of the new requirements and must comply with the challenges of today's modern world. The online toolkit, the e-learning material and its learning management system, which has been developed for three years in an international partnership, may be useful to prepare agricultural specialists for our knowledge-based information society.

\section{References}

3waynet Inc. 2004. LMS Evaluation User Guide, Commonwealth of Learning, viewed 9 September, 2013, http://www.col.org/PublicationDocuments/pub_04LMSEvaluation.pdf

Alecu I. N., Marcuta L., Marcuta A., Angelescu C. 2011. The role of an E-learning platform in the sustainable development of the online learning at the University of Agricultural Sciences and Veterinary Medicine, Distance Learning Department, Bucharest, Scientific Papers Series Management, Economic Engineering in Agriculture and Rural Development, 11(2): 5-8.

Al-Qutaish R. E. 2009. Measuring the Software Product Quality during the Software Development Life-Cycle: An International Organization for Standardization Standards Perspective, Journal of Computer Science, 5: 392-397.

Basu A. 2005. Assuring Software Quality with ISO 9126, IT Management, pp. 28-29.

Benson L., Elliott D., Grant M., Holschuh D., Kim B., Kim H., Lauber E., Loh S., Reeves T. 2001. Heuristic Evaluation Instrument and Protocol for E-Learning Programs, Draft of September 5, 
2001, University of Georgia, viewed $9^{\text {th }}$ September, 2013, http://treeves.coe.uga.edu/edit8350/heureval.rtf

Bit media e-learning solutions. 2009. Content Development, Bit media, Szeged.

Delf P. 2013. Designing effective eLearning for healthcare professionals.Radiography. 19(4): 315320.

Dillenbourg P. 2000. EUN Conference 2000: «Learning in the New Millennium: Building New Education Strategies for Schools » Workshop on Virtual Learning Environments, viewed 9 September, 2013, http://tecfa.unige.ch/tecfa/publicat/dil-papers-2/Dil.7.5.18.pdf

DNA Analyst Training: Benefits of e-Learning, viewed $5^{\text {th }}$ September, 2013, http://www.nfstc.org/pdi/Subject00/pdi_s00_m03_02_a.htm

Gaceu L., Danila D., Ola D. 2010. Continuing education in agri-food area - a challenge for information tehchnology, Journal of EcoAgriTourism, 1(1): 188-196.

Gaceu L., Gruia R., Danila D. 2009. Education In Food And Tourism Area Using Moodle Management Courses System in Transilvania University of Brasov, AVA2009 conference, Debrecen, March 26-27, 2009, 548-555.

Ghirardini B. 2011. E-learning methodologies. A guide for designing and developing e-learning courses. Food and Agriculture Organization of the United Nations. Rome. Viewed $27^{\text {th }}$ January, 2014, http://www.fao.org/docrep/015/i2516e/i2516e.pdf

Hampel Gy. 2010. Evaluation Handbook, Inno-Motive Nonprofit Ltd, Szeged.

Herdon M., Lengyel P. 2008. Multimedia and e-Learning integration for supporting training programs in agriculture by MOODLE. International Advanced Workshop on Information and Communication Technologies for Sustanable Agri-production and Environment Conference proceedings., 162-169.

Inno-Motive Nonprofit Ltd. Hungary, Bit media e-Learning solution GmbH \& Co Austria, Vakaru Lietuvos versio kolegija Lithuania, Inovaformacao - Prestacao de Servicos de Formacao Pro. Lda Portugal. 2010. SeeS-SME's e-learning to e-work efficiently, Progress Report, Szeged.

Inovaformação, Lda. 2010. SeeS-SME’s e-learning to e-Work efficiently. Sectoral Survey Report v1.1.

Lee Y., Lee J., Lee Z. 2002. Integrating Software Life Cycle Process Standards with Security Engineering. Computers and Security 21(4): 345-355.

Morrison G. R., Ross S. M., Kemp J. E., Kalman H. 2010. Designing Effective Instruction. John Wiley \& Sons. New York.

Munkhtsetseg N., Uyanga S. 2013. Implementation of E-Learning System: Findings and Lessons Learned. Intelligent Information Management, 5(1): 18-24

Nauris P. 2010. Moodle implementation at the Latvia University of Agriculture Information Technology System Architecture, Research for Rural Development - International Scientific Conference, 2: 204-207.

Palkova Z., Schwarz P., Floris N., Schwarzova L., Bandlerova A. 2013. European projects as a tool for improving farmers skills via modern information technologies, Scientific Papers Series Management, Economic Engineering in Agriculture and Rural Development, 13(2): 449-453.

Paulins N. 2010. MOODLE implementation at the Latvia University of Agriculture information technology system architecture. Annual 16th International Scientific Conference. Research for Rural Development. Development 2010. Conference Proceedings. Jelgava. Volume No. 2: 204207.

Sideridis A. B., Koukouli M., Antonopoulou E. 2010. ICT and farmers: lessons learned and future developments, Journal of Agricultural Informatics, 1(2): 35-41. 